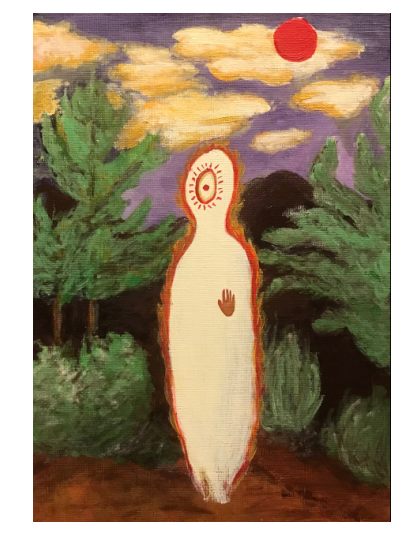

\title{
Interview: Waste, After the Revolution
}

Riccio, Alex

Laborwave Radio

laborwaveradio@gmail.com
Haverkamp, Andrea

Engineering, Social Justice, and Peace andrea.haverkamp@outlook.com

How to cite this text: Riccio, A., Haverkamp, A. (2021). Interview: Waste, After The Revolution. International Journal of Engineering, Social Justice and Peace, 8(2), pages 140-148.

Laborwave Radio and Opening Space for the Radical Imagination present an interview between podcast host Alex Riccio and Andrea Haverkamp recorded as part of our series After the Revolution. This podcast and interview series is inspired by a desire to offer more than a diagnosis of what is wrong with today, by further focusing on what we might be able to bring about. We begin by highlighting the importance of considering one feature of society than imagining what it might look like after the revolution, and finally offering some ideas on how get to this revolutionary society. This paper is the transcript of the interview with edits for readability.

\section{Key Words:}

Waste management, Revolution, Anti-Capitalism, Production 


\section{Laborwave host, Alex Riccio (LW):}

I'm thinking about waste. I have two quick questions for you to get this conversation started. How do you define waste? Secondly, why does it matter and why is it important to think about considerations around waste for today's present society?

\section{Andrea Haverkamp (AH):}

When I think about waste in the most common way, it is an output, a by-product, something that is often the end result. When I think about waste, I think about everything that goes to a landfill, everything that goes to recycling (much of which still goes to a landfill), and everything that ends up in our water and environment. I think it's different than pollution in that waste is often considered - even the term waste management - as trash, garbage, sewage, gunks that need to be specifically cared for, treated, disposed of, and put somewhere safe.

\section{LW:}

You gave waste a distinction from pollution. That's interesting to me because I when the word waste comes to my mind, that tends to be where I go: contaminants, pollution, bad things.

\section{AH:}

I'm using it in the sense that waste is collected and treated (in waste management systems). When we talk about pollution, a lot of that goes straight into the atmosphere and there it is, it's in the atmosphere or it's in the water. Waste can certainly go into the water as well, but in common vernacular waste is your trash, your recyclables, where your water goes after you let out the bathtub or the sink and everything that gets thrown in or outside the trash can. (https://energyeducation.ca/encyclopedia/Pollution_vs_waste_)

\section{LW:}

So, what's so important about waste?

\section{AH:}

What's important about waste is it is the by-product of capitalism. Capitalism is a consumption and disposability culture. Consumer capitalism creates a dynamic in our society where we produce more trash than I think anyone can even fathom without going into numbers. We have a growing trash crisis in the globe. We do not know exactly where to put it all. We don't exactly know what's in every ton of trash and a lot of it - almost all of it - will be around for thousands of years. All I think when I see a plastic bottle, a plastic bag, even a trash bag, or a bag that I pick up my dog's waste on a walk, is that the bag will be around for thousands of years. It just disappears behind a hill in Corvallis, Oregon about 10 miles out. It's the societal equivalent of cleaning your bedroom by taking a broken pen and just shoving it behind your bed - hoping you never see it again, and forget you put that broken pen behind your bed. 
That is what we do as a global society with trash, waste. And in the United States we have the privilege of "waste services." Other countries don't have what we have, such as landfills, which are a very fancy backyard to throw all this trash. Elsewhere, it just goes into their water, into their ground, into their soil, into their crop field. This phenomenon of plastic based waste has not existed for 200,000 years of human history. The waste and landfill crisis are a product of the past couple of hundred years, specifically the last hundred when oil and petroleum use skyrocketed around World War II and afterwards in the United States. It created what a lot of Capitalists will call "the most advanced progress in human history" - but it is unsustainable, and it is destroying our way of life right beneath our feet, hidden behind the hills.

\section{LW:}

I've heard stories and I'm hoping you can elaborate and give some more of the details about this, but things like garbage island, where there's apparently just tons of plastic floating around in the middle of the ocean. What is that? How damaging is that for that to even exist?

\section{AH:}

Yeah, it's unprecedented that we're creating entirely new landscapes out of single use plastics. Styrofoam, metals... an island sized mound of waste that developed because of the way the ocean pushed all this trash in its natural wave patterns into a certain area where they conglomerated. Or these landscapes look like natural hills when you drive up North of Corvallis, Oregon. There are landfills between where I live in Corvallis, Oregon, and Monmouth, the city North of us. They look like hills when you drive by it. But - they're human made piles of garbage that are covered, that are sealed, and have vegetation planted on top to hide the fact that the supposed hill is over a hundred feet of trash.

\section{LW:}

I'd like to explore a little bit more what you were saying about the disposability culture of waste under capitalism. There's a couple of things there that sound interesting to me. One is that waste under capitalism is a particular phenomenon that doesn't necessarily exist prior to this mode of production. But it also sounds like you're suggesting that there's a kind of relatedness to the way that we deal with our own waste byproducts and the way we maybe even treat human beings and nonhuman animals.

\section{AH:}

That is completely true. Absolutely. Disposability culture is talked about in a lot of ways. One is with human beings: which humans are disposable, which lives we're seeing in the COVID-19 crisis are disposable, or such as troops as disposable when you throw them to the slaughter. Our nurses and our retail workers and service workers are seen as disposable and a calculated human cost in the COVID-19 crisis. It is painfully evident in these times that disposability culture is created under white supremacy and legacies of colonialism: which lives and which lands and which bodies are to be disposed of. This disposability logic also moves into our daily life, with single use cups, single use straws, but at the big structural level we've designed the society 
bottom up and top down and to dispose of human beings and to dispose of products to support continual resource extraction and continual production. You can't have continual extraction and continual production without continual disposal and degradation. It's built into the very fabric of capitalism that we must dispose so that we can extract to create again.

\section{LW:}

Say what the impacts on broader climate change are when it comes to the way we deal with waste under capitalism. Like, how much does our system of disposing that you're talking about, you know, using single use items for the sake of recycling, this mode of consumption and production, how much does that actually impact the health of the planet and climate change itself?

\section{AH:}

Under capitalism, consumption is the main driver of climate change. If we're talking not only about a handful of companies, right? What are those handful of companies doing?

I think contrary to what a lot of media likes to push, that gas and fuel and oil is extracted primarily for cars. Sometimes jets. A lot of oil is also pulled out of the ground to form various plastics, which go into our sponges, our single use items. into producing so our consumer electronics, our cars, you know, plastics literally shape the world around us. I am skeptical that anyone is listening (or reading) this without plastic involved. The impacts on our climate are catastrophic. I deeply worry about the status of this planet if consumption, disposal, and unfettered waste production continue.

People talk about climate change often in terms of production and extraction of oil, but waste management is what keeps our minds completely off the fact that we are generating pounds and pounds, and tons and tons, of waste in our neighborhood every month, year and day. The waste gets picked up off our curb and put out of our minds - and we continue the cycle again. Until we bring focus onto waste, the end product, the output of capitalism and consumerism, we really can't get at the source.

\section{LW:}

The conversation really does get to the point where it becomes quickly overwhelming. I would like to talk soon about what it looks like after the revolution, understanding that that's going to be a very challenging subject to tackle. Before we do that to just focus a little bit more on what I think your emphasis is on the structural level of waste. Because for me, when these conversations come up, it's extremely common for people to start feeling pangs of individual guilt and shame over their own lifestyle and consumer choices. I want to hear your thoughts about that. Like how much individual agency is there within this whole kind of waste system that we're talking about and how much focus should we maintain on the kind of structural elements of capitalism when we're discussing waste?

AH:

Yeah, it is an absolute structural issue. No individual is making plastic cups. No one here with us 
is making cardboard wax covered cups. No one, no individual is responsible for the giant industries and facilities and factories producing those products that then structure our lives. I have tried my darndest, you know, I have my water bottle, my coffee mug, my refillable containers that I take to the co-op and get bulk items, I say no to certain things like paper towels, you can try all that all you want too. As an individual, we can't feel too much guilt. We should try our honest, non-guilt best to limit our productions of waste of course. But it is the social and economic structure of extraction and consumption which creates the waste. Until we tackle it as a society and overthrow the dominant powers, we can't put too much blame on ourselves.

\section{LW:}

I think that's a perfect segue - let's talk about what happens after we've toppled those dominant powers, after we've shocked capitalism off our backs and put it into the dustbin of history. What does waste look like after the revolution?

\section{AH:}

The concept of trash cans and of landfills as we know it, and recycling, those are almost all gone. We will, after the revolution, use these landfills as the new gold mines. We have put so much plastic in there that will not be going away for thousands of years, and metals and rare earth minerals, right? We can get those back out! We will no longer have our lives dominated by single use items. That is not to say that we're not going to retain the ability to produce certain life-saving medical interventions and prescription drugs that that are necessary. We're going to find that sweet spot where we can preserve as much care for our elders, newborns, children, our health needs, and our care needs all while practically eliminating resource extraction, refinement, and subsequent disposal. What that looks like is a very careful and community-based model of reuse.

I think - today - we could shut down every factory that produces ceramic mugs, reusable water bottles, and disposable cups. I think we'd be fine for hundreds of years. I think we have enough cups made. We really do. For things like that, we won't need to produce. No matter what, after the revolution, given the Earth's population, no one would want to go back to measles, mumps, and rubella. There will need to be a small-scale production of certain goods, not in the consumer capitalist model, but items which will be able to save lives.

We have another elephant in the room regarding waste, which is sewage. Our dishwater, our bathroom water, there's incredible technology which already exists to harness the byproducts from our sewage and from our wastewater and produce energy. In my master's program, I did a design project and found that even just one wastewater facility the size of the one in south town in Corvallis, Oregon could theoretically power a small village with electricity. In the future, it looks less like wastewater is a gross or shameful thing to talk about or that it's shameful to talk about where the sewage goes, but instead we get very excited about it! "We are done with a bagwhere does it go? And what happens after we flush?" 


\section{LW:}

I'm struck by something you said where you describe landfills of the future as the gold mines in that society. It makes me think a little bit more about the production of value, right? Like for me, capitalism really comes down to the way that we have assigned and ascribed value on lives, on the environments, on fictitious forms of currency, right? Gold doesn't really have that much value that we subscribe to it. And you're suggesting in my understanding that the entire conceptions around what will be seen as valuable and what will be seen as not as valuable will be completely shifted in this future society around waste.

\section{AH:}

Oh, absolutely. You know, if I had to do an art project, if I was a visual artist, sometimes people draw these utopian visions of what life looks like after the revolution, perhaps everyone is in a field putting in their work towards the crops. That's certainly a part of it.

Perhaps everybody is in this big, smooth picture-perfect Sci-Fi landscape and there's space travel involved. I don't agree with any of that though.

I think we're going to live in trash world. We've already created trash world. We must learn to embrace, to nurture Earth back to where it needs to be while also being keenly reminded that this trash ain't going anywhere. Even in Northern Europe, where they have waste-to-energy facilities, and some areas actually import trash to burn for electricity. You know, at the end of the day, you still have waste in the form of ashes and what couldn't burn.

It's about learning to sit with these things and not avoid them, not to shove what we view as waste off to the curb to be picked up by some trucks every week, but learning to really sit with it and to live with it. I think if we all quit throwing out our trash for a month, we would see that so many of the cups and the bags have alternative uses and we can turn off a lot of these single use item factories overnight. We'll realize that we need to come up with - as a community - creative ways to reuse and re-imagine what these materials can be.

\section{LW:}

It sounds like the stigma around this stuff would really be shifted and probably even our conceptions of ourselves as humans will probably be shifted in this future society. I wanted to share a story from my own history in participating in - a shout out to the Institute for Advanced Troublemaking - the loosest sense of an anarchist camp. One of the things that they had done at this place in Massachusetts was they used a collective house as their school site. They created an entire kitchen from scratch that they built in the front yard and they had compost toilets and solar panels, showers all over the property. For me, the compost stuff was completely new, completely gross at first. It was amazing how much intention and focus they had done in terms of an ecological sustainable system for just their little plot of land and how much you get used to and kind of normalize composting your own byproducts, your own waste. So that's a small micro scale iteration of that. What do you think that could look like on a more scaled up sense? Like, the stigmas around these things and the ways that we orient ourselves towards our own waste? 


\section{LW:}

I think the stigmas that are associated with waste are endemic to our society, whether it is jokes and denigration of people who work with trash, in sanitation, or waste / wastewater. I think removing that stigma removes the associated stigma about our own bodies and what's seen as shameful and what's seen as gross. And what we've been told are gross sights or smells or sounds. I think removing that stigma liberates us as human beings at a level that I don't think we can fathom, but I would like to think as I'm fathoming it, that after the revolution, this will make it a valiant contribution to our culture and to our neighborhood to care after our little local microsystems of sewage production and composting. I think right now, sending everything to a single facility for recycling or composting processing is just not as tenable.

We can continue to use our system though, as far as municipal water and municipal wastewater is concerned. Since that infrastructure is built, we don't need to tear it down. We got these pipes? We might as well use them. Again, when it comes to water and wastewater, we tend to think we individually are the problem. If I flush less, the problem will be better. Well, the biggest problems with water are that our treatment plants must treat industrial waste. We have a system of regulation where factories across the river that supply our drinking water are allowed to put toxins and factory byproducts into the water. Then we must treat that waste too as part of regular water treatment. Getting rid of these unnecessary factories will allow our municipal water and wastewater systems to continue for quite a long time with less strain. And if, and when, these systems start to break down, I think decentralized compost toilets, and cycling out where that compost goes and how it's dealt with like the way you were talking about is perfectly normal, but for places that have wastewater systems, we don't necessarily need to abandon them or tear them up.

\section{LW:}

I'm wondering about the management of this system of waste and its implications and broader governing structures. So, as you're talking about some of these things we already have in our existing paradigm and we can reuse them and reconfigure them in ways that are more beneficial, how does that implicate governments? What kind of scale of government would that require and how local would that system be versus regional or national or international?

\section{AH:}

There's a lot of watershed-based approaches, which are really enticing. I think first and foremost is a centering of Indigenous peoples and in the Indigenous systems of governance and land management and care and stewardship that emerge. And at that level, I think state and federal governments as we know them will not exist nor would they have any meaningful input. It is an extremely local and extremely prestigious position to be in, to be talking about not only the means of production, but the means of waste sanitation and managing waste. I think that those positions would be democratic. I think that they would be of the highest importance. We care about what we eat. We need to think just as deeply about what happens after. 


\section{LW:}

It's always interesting to get a broad view of this stuff and articulate it in the ways that you have. It's been very rich and interesting, and I'd like to get somewhat more concrete for listeners and for myself by asking you to walk us through a day in the life after the revolution.

\section{AH:}

When I wake up, I don't turn on a light bulb. I wake up naturally as the sun wakes up. When I go to brush my teeth in the morning, there is a horse hair and wood toothbrush that I can use. I would be able to still wash my hair, wash my hands, because I think that where I am we have water infrastructure that should keep going for several hundred more years with minimal repairs. All the food I eat and drink would be in reusable, recycled, or taken-from-the-trash containers.

I think refrigerators wouldn't really exist. I think we could have (non-electric) coolers. For people who balk at that, I would say that more than half of the world's population right now lives without a refrigerator. Refrigerators are very modern in terms of capitalist production. I don't think there would be a need for a refrigerator for me to go eat. I would work my day, whether it is labor of the household, labor of care, labor of food and all throughout it. When I use the restroom, there is either a vault toilet, or a compost toilet. A vault toilet is kind of like an outhouse that I can use. Plant materials can be used instead of toilet paper being produced. Yeah. I think that everything we have would be junk that we make work. If cell phone towers continue to exist, we don't need to tear them down, but if they're still running, I think these phones are from the trash and repair parts are sourced from the trash. There's no new iPhones after the revolution. We work our hardest to make them last as long as we can. We're not going to replace the oil fields in this future with lithium fields. I think after the revolution, that day sounds pretty relaxed.

\section{LW:}

It sounds like a very beautiful society. I want to segue into what I think is often the most difficult part of these conversations beyond just expanding our imagination - how do we get there from here to there? What does that process look like? I want to like focus a little bit on what you just said, that there are no new iPhones after the revolution. While that sounds amazing to me, for some, let's be honest, some capitalist boot licker, that's going to sound like the most terrifying future scenario ever said, that there's no new computers. The pathway to this future society sounds like it will be a highly, highly contested. What do you think the pathway looks?

\section{AH:}

If I could wave a magic wand- tomorrow, everyone would realize the magnitude of our climate emergency. We are in the climate demolition. We are terraforming. Every single factory that produces consumer electronics, consumer plastics, and prepackaged, processed materials and goods that aren't essential for food or medical needs - fire trucks would go out there. Emergency crews would go out to these factories and shut these factories down. Immediately. Shut them down immediately. That's how we get there. 
Our system / approach of environmental regulation - I can say this as someone who used to work at the EPA - it just mitigates disaster. It doesn't remove disaster. It regulates it, manages it, and allows pollution and waste. It doesn't eliminate it. We got to immediately just shut these factories down. What are we going to do next? Well, that's something we'll all have to figure out together, but I always return to the example of the plastic cup.

If you want a soda at McDonald's the day after we shut down every cup factory, bring a cup. If you don't have a cup, I'm sure there's a recycling store that has one. If they don't, go and ask your neighbor. We produce more cups than people who exist in the United States every year, right? I think when you go from this place of the most illogical and unnecessary capitalist production and explain it to someone, "oh, we just shut down the cup factories" it can be fine. Then you extend it. Eventually we'd say, "well, we've got reasonably enough computing devices for every neighborhood, every collective to have access to the internet and telecommunication in a way that has never existed in human history." We shut those down. How does it happen? A mass movement we organize when we realize that production of these things will wipe out humanity. We have no choice but to shut those factories down, and we just keep going.

We keep going from superfluous devices to those where we start to say, "well, I don't know if we could shut down the pacemaker factory. Can we maybe not?" Right. This is something that we'll have to talk about when we get there - medical syringes and needles, how much metals do we need? I think when you get down to the brass tacks of what we need to maintain human health and safety and care for each other, you'll find that we could likely recycle, refine and dig up out of the landfills, the materials, plastics, and metals that we need for essential items like pacemakers or syringes. I think we can go step wise. I think that's how we get there.

Very first thing tomorrow, though, we shut down the plastic bottle and plastic cup factories. We don't need them.

LW:

I love that your first target of contest station is the cup factory, as opposed to the monarchs or the president.

\section{AH:}

Right? I mean, you're right. (Capitalism) is so structural. (The monarchs and the presidents) are beholden to the cups. The cups are not beholden to them under consumer capitalism. We've created a runaway train and this runaway train is the whole global economy. There's no single figurehead that we can shut down like we could shut down a factory that'll have the effects that we need. I use cups for a very specific reason because without water for 24 hours, a human is not in great shape. Drinking water and how we drink water is one of the most grounding concepts as a human being. We navigate water every hour. I think when you start to really look at how we have enough cups, I don't think anyone's going to (laughter). I laugh, because it's hard to say, but I don't think anyone out there listening to this podcast is struggling to find a cup. So yeah, I think it's one of the most basic things that we can all agree on - we need to shut down the cup factories. That's part of why I center on the cups. 


\section{LW:}

Do you feel that there's any existing practices or instances where we are modeling this future society around waste?

\section{AH:}

There's an intentional community in Washington state called Windward. It's a collective of people, about a dozen or less, who live on around a hundred acres up there. Their primary activity is they live off the land. They maintain their own sewage. They dig and harvest the crops. They have a pig and describe it to me as their bioreactor. They have one pig that can go through and of root up and till the plots for crops every year and eat the old roots. The pig turns these things into fat, into muscle. This pig can live for several years during this very intensive labor. For human bodies, they manage a cemetery which uses natural body burial, and they allocate a certain number of acreages for each body that they put in the ground. I think they model revolutionary waste management very well, and also what it looks like to live very remote, on very little, in what is not the most hospitable place. They're in the high mountain dry desert landscape. I think that those folks, after visiting them, I think they're doing a pretty good job. They use very little electricity. Do they have solar panels? No. Do they have wind energy? No. Do they generate it themselves? No, they generate negawatts (low or minimal electric energy consumption). They use virtually no electricity, but there is a hydroelectric dam 30 minutes from them on the Columbia River. We're not going to shut down this dam overnight. So, the most environmentally friendly thing in the short term is to run one wire out there while this dam is still an operation and get a little bit of electricity. That's one reason why I don't see solar panels or wind farms as the solution right now, because production of that new infrastructure is creating more waste and carbon emissions in the future. I think those folks are doing it quite well.

\section{LW:}

I want to give you the opportunity to conclude here with any final thoughts or things you want to make sure you articulate as we end this very expansive conversation.

\section{AH:}

We must learn to not only think critically about everything we put in plastic bags or garbage bags, which themselves will be around for hundreds of years - just the bags themselves. Not only what's in them. We must think very deeply about where they go and about why we put them there (landfills). We got to start loving waste, and I mean loving it. We talk about getting our hands in the dirt, but we don't talk about getting our hands in the feces, but that's an essential part of the human experience. We live, we eat, we produce human waste and we produce material waste. You shuck a piece of corn. Where does that go? It goes into the compost. Well, if you drink a plastic out of a plastic cup, what's that cup going to do? Exist in perpetuity. So, we got to start loving waste, wastewater, sewage, landfills, trash. These cannot be negative words. They must be joyful words. We need to get knee deep in this waste. We already live on a planet and in a society overwhelmed with trash, and the revolution will emerge from, and with, all of this waste and trash. 